Aksaray University
Journal of Science and Engineering
e-ISSN: 2587-1277
http://dergipark.gov.tr/asujse
http://asujse.aksaray.edu.tr

Research Article

\title{
An Investigation on the Soil Stabilization with Waste Tyres Materials in Granular Soils
}

\author{
Ertugrul Ordu ${ }^{1, *}$, Perihan Bicer ${ }^{1}$, Seyma Ordu ${ }^{2}$, Emine Gamze Abanozoglu ${ }^{1}$ \\ ${ }^{1}$ Namık Kemal University, Corlu Engineering Faculty, Dep. of Civil Eng., 59860 Tekirdag, Turkey \\ ${ }^{2}$ Namık Kemal University, Corlu Engineering Faculty, Dep. of Environmental Eng., 59860 Tekirdag, Turkey
}

-Received Date: 15 Mar 2017

-Revised Date: 02 May 2017

-Accepted Date: 11 May 2017

-Published Online: 17 May 2017

\begin{abstract}
The aim of this investigation is to research the improvement of sandy soils with additive materials. California Bearing Ratio (CBR) is commonly used to determine the characteristics of sandy soils which are improved by using additives. The CBR test estimates behavior of subbase and granular layers for flexible superstructures. Waste shredded tires are used as additives in accordance with the purpose of this study. A great majority of materials, which are considered as wastes in the world, consist of recyclable materials. Recycling these materials is imperative for being able to preserve environmental and natural balance, minimizing the damage inflicted upon nature and also for the country's economy. The improvement of ground with additive materials has been widely used since it is more economical than other stabilization methods. Recently, usage of industrial waste materials as additive materials has become popular. Investigations on utilization of waste tires in geotechnical engineering are being carried not only in our country but also in the rest of the world.
\end{abstract}

\section{Keywords}

Soil improvement, CBR values, Waste Tire, Compaction.

*Corresponding Author: Ertugrul Ordu, eordu@nku.edu.tr 


Aksaray University
Journal of Science and Engineering
e-ISSN: 2587-1277
http://dergipark.gov.tr/asujse
http://asujse.aksaray.edu.tr

Research Article

\title{
Kumlu Zeminlerin İyileştirilmelerinde Atık Lastiklerin Kullanılması Üzerine Bir Araştırma
}

\author{
Ertuğrul Ordu ${ }^{1, *}$, Perihan Biçer ${ }^{1}$, Şeyma Ordu ${ }^{2}$, Emine Gamze Abanozoğlu1 ${ }^{1}$ \\ ${ }^{1}$ Namık Kemal Üniversitesi, Çorlu Mühendislik Fak. İnşaat Müh. Böl. 59860 Tekirdağ, Türkiye \\ ${ }^{2}$ Namık Kemal Üniversitesi, Çorlu Mühendislik Fak. Çevre Müh. Böl. 59860 Tekirdağ, Türkiye
}

-Gönderi Tarihi: 15 Mar 2017

-Düzeltme Tarihi: 02 May 2017

-Kabul Tarihi: 11 May 2017

-Cevrimiçi Yayın Tarihi: 17 May 2017

\section{Özet}

$\mathrm{Bu}$ inceleme çalışmasının amacı kumlu zeminlerin katkı malzemeleriyle iyileştirilmesinin araştırılmasıdır. Katkılarla iyileştirilen kumlu zeminlerin karakteristiklerinin tespit edilmesinde, Kaliforniya Taşıma Oranı (CBR) deneyi kullanılır. CBR esnek üst yapılar için alt temel ve granüler tabakaların davranışını belirler. Çalışmanın amacı doğrultusunda katkı malzemesi olarak atık lastik parçacıkları kullanılmıştır. Dünya üzerinde atık olarak değerlendirilen maddelerin büyük bir kısmı geri dönüştürülebilir malzemelerden oluşmaktadır. Bu malzemelerin yeniden kullanılarak geri dönüşüme katılması çevrenin ve doğanın dengesinin korunabilmesi, doğaya verilen zararın minimuma indirilebilmesi ve ülke ekonomisi açısından oldukça önemlidir. Zeminlerin katkı maddeleri ile İyileştirilmesi diğer iyileştirme yöntemlerine göre daha ekonomik olmasından dolayı çok geniş bir şekilde kullanılmaktadır. Son zamanlarda endüstriyel atık maddelerin bu amaç için kullanımı ön plana çıkmıştır. Geoteknik Mühendisliği alanında da atık lastiklerin kullanılabilirliği araştırmaları tüm dünyada ve ülkemizde sürdürülmektedir.

\section{Anahtar Kelimeler}

İyileştirme, CBR değeri, Atık Lastik, Kompaksiyon.

\footnotetext{
*Sorumlu Yazar: Ertuğrul Ordu, eordu@nku.edu.tr
} 


\section{GÍRİ̧̧}

$\mathrm{Bu}$ çalışmada, katkı malzemeleri kullanımının kumlu zeminlerin iyileştirilmeleri üzerindeki etkileri araştırılmıştır. Katkılarla iyileştirilen kumlu zeminlerin karakteristiklerinin tespit edilmesinde, Kaliforniya Taşıma Oranı (CBR) deneyi kullanılır. CBR esnek üst yapılar için alt temel ve granüler tabakaların davranışını belirler. Çalışmanın amacı doğrultusunda katkı malzemesi olarak da atık lastik parçacıkları kullanılmıştır.

Zeminlerin katkı maddeleri ile iyileştirilmesi diğer iyileştirme yöntemlerine göre daha ekonomik olmasından dolayı çok geniş bir şekilde kullanılmaktadır. Son zamanlarda endüstriyel atık maddelerin bu amaç için kullanımı ön plana çıkmıştır. Geoteknik Mühendisliği alanında da atık lastiklerin kullanılabilirliği araştırmaları tüm dünyada ve ülkemizde sürdürülmektedir.

Hafif dolgu malzemeleri geoteknik mühendisliğinde; çok yumuşak zeminler üzerinde hafif dolgular oluşturularak oturma ve taşıma gücü problemlerinin çözümünde, heyelan veya kayma potansiyeli yüksek şevler üzerinde dolgu teşkil edilmesinde, dayanma yapılarına gelen yatay itkilerin azaltılmasında kullanılmaktadır. Doğal malzemeler olan; ponza taşı, talaş/yonga gibi orman ürünleri sanayi atıkları, kolaylıkla elde edilebildikleri bölgelerde hafif dolgu malzemesi olarak evvelden beri kullanılmaktadır.

Bununla birlikte, kullanılmış oto lastiği parçaları, termik santral uçucu külü, hafif dolgu malzemesi olarak kullanılmaya en elverişli endüstriyel atıklardır. Endüstriyel atıkların depolanması çevre açısından bir problem olarak ortaya çıkmaktadır. Bu problemi çözmenin bir yolu da bu malzemeleri hafif ve katı hale dönüştürerek zemin yapılarında kullanılmalarını sağlamaktır.

Her yıl geniş hacimli üretilen atık lastikler kullanım ömürlerini tamamlayınca bir bertaraf problemi oluşmaktadır. Atık lastikler, inşaat mühendisliği uygulamalarında kullanılabilecek ilginç teknik özelliklere sahiptirler. Atık lastik malzemelerin karakteristik özelliklerinin bazıları: düşük yoğunluk, yüksek elastikiyet, sertliğin az oluşu, yüksek drenaj kapasitesi ve yüksek ısı yalıtım kapasitelerinin olmasıdır. Bu özellikleri, yenilikçi bir şekilde malzemenin kullanım olanaklarını açacaklardır. Atık lastiklerin zemin iyileştirmelerinde kullanılması ile malzemenin yoğunluğunda azalma, tokluk, sertlik ve darbe direncinde artış ile 1sı ve ses yalıtım özelliklerinde önemli iyileşmeler sağlanabilecektir.

Tüm bir lastiğin, çeşitli endüstriyel işlemlerden geçirilerek, farklı boyut ve geometrilerde alternatif bir malzeme olarak kullanımı; başta ABD olmak üzere, birçok gelişmiş ülkede atık lastiklerin yönetimi ile ilgili sorunları büyük ölçüde azaltmıştır. 
Dünya üzerinde atık olarak değerlendirilen maddelerin büyük bir kısmı geri dönüştürülebilir malzemelerden oluşmaktadır. Bu malzemelerin yeniden kullanılarak geri dönüşüme katılması çevrenin ve doğanın dengesinin korunabilmesi, doğaya verilen zararın minimuma indirilebilmesi ve ülke ekonomisi açısından oldukça önemlidir. Atık lastik katkısının zemin numunesi üzerindeki etkisini belirleyebilmek için laboratuvarda kompaksiyon ve CBR deneyleri gerçekleştirilmiştir. Tabii (Doğal) zemin örneği üzerinde kompaksiyon deneyi yapılarak optimum su muhtevası ve maksimum kuru birim hacim ağırlık belirlenmiştir. CBR deneyleri tabii zemin numunesi yanı sıra tabii zemine $\% 0.1$ ile $\% 0.2$ oranlarında atık lastik katılarak \%8, \%8.5, \%8.75, \%9 ve \% 9.5 su muhtevaları değerlerinde tekrarlı olarak yapılmıştır. Deneysel çalışmanın sonuçları değerlendirilerek gerekli öneriler yapılmıştır.

\section{MALZEME VE YÖNTEM}

\section{1. Önceki Çalışmalar}

Kalinski ve Hippley, Portland çimentosu ve uçucu kül ilavesiyle su muhtevası üzerinde çimento içeriğinin etkisini araştırmıştır [1]. Su muhtevasını bulmak için Proktor ve modifiye Proktor deneyleri yapılmış ve mukavemetini ölçmek için de serbest basınç deneyleri yapılmıştır. Angın, Trabzon İçme Suyu Arıtma Tesisinde suyun arıtılma işlemi sonucunda atık olarak oluşan çamur katkı maddesi olarak kullanılabilirliğini araştırmıştır [2]. Şenol ve Edil, oldukça düşük taşıma gücü özelliğine sahip yumuşak ve kısmen organik malzeme içeren zeminlerin, yol inşaatında uçucu kül kullanarak taşıma gücünü arttırmak için stabilizasyonun sağlanmasına ait araştırma sonuçlarını sunmuşlardır [3]. Ghazavi, granüler kauçuk ile üniform kum zeminlerin stabilizasyonu konusunu çalışmıştır [4]. Yoon ve arkadaşları, eski kamyon lastiği kullanarak güçlendirilmiş zeminin taşıma kapasitesi ve oturması üzerine bir çalışma yapmıştır [5]. Atık lastiklerin kum zeminde kullanılması yoluyla faydalı olacağı düşünülerek laboratuvarda plaka yükleme deneyleri yapılmıştır. Tan ve arkadaşları, yaptıkları çalışmada 0.06-0.5 mm tane çapı aralığına sahip kum, değişik oranlardaki bentonit, kil, uçucu kül ve silis dumanı ile stabilize edilerek kayma direnci ve kompaksiyon parametrelerinin değişimlerini incelemişlerdir [6]. Sivapullaiah ve arkadaşları, kırmızı toprak zemine $\% 20$ bentonit, $\% 1$ çimento ve $\% 1$ kireç katkısı üzerinde çalışmışlardır [7]. Kompaksiyon deneyinden elde edilen optimum su muhtevasına göre numuneler hazırlanmıştır. Değişik katkı oranları ile hazırlanan numuneler 0, 7 ve 28 gün kür edilerek konsolidasyon, serbest basınç deneyi gibi deneylere tabi tutulmuştur. Deneyler sonucunda, zeminin kompaksiyon özelliklerinin değiştiği görülmüştür. Çokça ve Toktaş, dispersif bir zeminin C tipi uçucu kül ile stabilizasyonunu araştırmışlardır [8]. Değiş̧ik oranlarda $(\% 0, \% 3, \% 5, \% 7, \% 10$ ve \%13) C tipi uçucu kül dispersif zemin numunesine katılarak uçucu kül ilavesinin indeks, mukavemet ve konsolidasyon özelliklerine etkisine 
bakmışlardır. Kaniraj ve Havanagi ise çimento ile uçucu kül stabilizasyonu hakkında bir çalışma yapmışlardır [9]. Tüdeş, kireç ve çimento katkısı ile zeminlerin stabilizasyonunu amacıyla Doğu Karadeniz bölgesi zeminlerinden üç tanesini seçerek zeminlerin fiziksel özellikleri rutin deneylerle, mineralojik özelliklerini de DTA (Differantial Thermal Analysis) ve XRD (X 1şı1nı) deneyleri ile belirlemiştir [10]. Seçilen zeminler değişik oranlarda çimento ve kireç katkılarıyla standart bir enerji ile sıkıştırılmış ve kayma direnci parametreleri elde edilmiştir. Katkısız durumda aynı enerji ile sıkıştırılan zeminin kayma parametreleri belirlenerek elde edilen iyileştirmeler karşılaştırılmıştır. Mandal ve Vishwamohan üç değişik genişleyen kile katkı malzemesi olarak hindistan cevizi lifi ve hint keneviri lifini tabakalar halinde geotekstil gibi ekleyerek Kaliforniya taşıma oranı deneyleri ile davranışını araştırmışlardır [11]. Krishnaswamy, zeminin dayanıklılık oranının katkı malzemesi ile arttığı sonucuna varmıştır [12]. Li, zemin stabilizasyonunda çimento, uçucu kül ve EER kullanımını araştırmıştır [13]. EER Japonya'dan getirtilen kimyasal bir karışımdır ve Li’nin çalışmasında zemine sadece çimento katkısı ilavesinden daha fazla mukavemet kazandırmak için çimento, uçucu kül ve EER katkısının çok daha etkili olacağı vurgulanmaktadır.

Literatür çalışmaları, lastik parçacıklarının, kumun mekanik özelliklerini iyileştirdiğini göstermektedir. Bunun yanında, kum içerisine lastik parçacıklarının yerleştirilmesinin, kumlu zemin malzemelerine bir donatı etkisi kazandırdığı ve lastik içeriği, şekil oranı, kompaksiyon değerlerinin, karışımın kayma mukavemetini etkileyen önemli parametreler olduğunu ortaya koymaktadır.

\subsection{Deneysel Çalışma}

Bu çalışma, N.K.Ü. Çorlu Mühendislik Fakültesi, İnşaat Mühendisliği Bölümü Geoteknik Ana Bilim Dalı Laboratuvarında gerçekleştirilmiştir. NKÜ Çorlu Mühendislik Fakültesi Yerleşkesi civarından alınan zemin numuneleri, çuvallar ile taşınarak NKÜ Çorlu Mühendislik Fakültesi İnşaat Mühendisliği Geoteknik Ana Bilim Dalı Laboratuvarına getirilmiştir. İstanbul Bölgesi'nde faaliyette bulunan bir lastik parçalama ve ögütme tesisinden; 0.0-0.6 mm/0-30 mesh ile 0.6-2.0 mm/30-10 mesh boyutlarında öğütülmüş lastikler temin edilmiştir. Mesh boyutlarındaki lastik parçacıkları; bu parçalama ve öğütme tesisinde, atık otomobil lastiklerinin çelik liflerinden ayrılarak, belli boyutlarda öğütülmesiyle elde edilmiş̧lerdir. Çalışmada, atık lastik katkı malzemesi olarak 0.0-0.6 mm/0-30 mesh tercih edilmiş ve uygulanmıştır. Laboratuvara getirilen kumlu zemin numunelerin fiziksel özelliklerini belirleyebilmek için elek analizi, hidrometre analizi ve özgül yoğunluk deneyleri yapılmıştır. 
$\mathrm{Bu}$ çalışma için zemine ait granülometrik özellikleri (dane çapı dağılımı) elek ve hidrometre analizi deneyi ile belirlenmiştir. Şekil 1'de elek analizi ve hidrometre deneylerinin değerlendirilmesinden elde edilen granülometri eğrisi görülmektedir. Bu deneyler sonucunda zemin sınıfı, birleştirilmiş zemin sınıflandırma sistemine (USCS) göre kötü derecelenmiş ince ve kötü kum (SP-SC) olarak belirlenmiştir.

Zemine ait granülometri eğrisinden, zeminin çakı1, kum, silt ve kil oranları için elde edilen değerler Tablo 1'de, dane çapı eğrisinden değişik çap değerleri ile üniformluk katsayısı ve derecelenme katsayıları da elde edilerek Tablo 2'de verilmişlerdir.

Tablo 1. Zemin örneğine ait çakıl, kum, silt, kil oranları

\begin{tabular}{llll}
\hline Çakıl (\%) & Kum $(\%)$ & Silt (\%) & Kil (\%) \\
\hline 4.11 & 79.9 & 5.54 & 10.45 \\
\hline
\end{tabular}

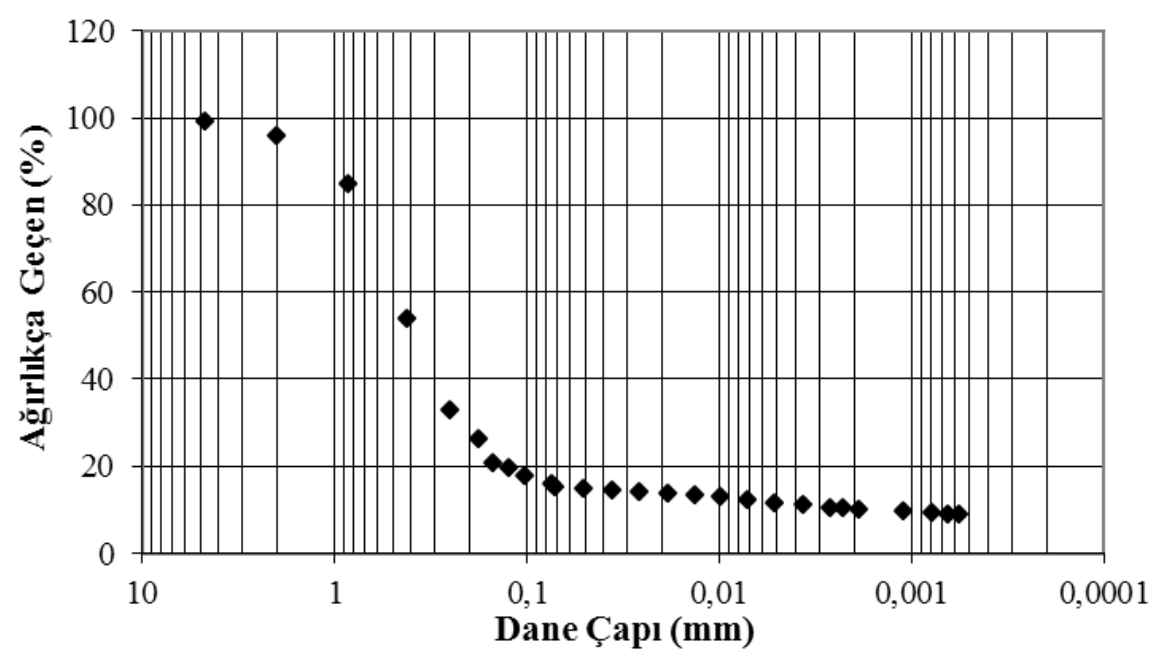

Şekil 1. Zemin örneğine ait granülometri eğrisi

Tablo 2. Zemin örneğine ait üniformluk katsayısı ve derecelenme katsayısı değerleri

\begin{tabular}{ccccc}
\hline $\mathrm{D}_{10}(\mathrm{~mm})$ & $\mathrm{D}_{30}(\mathrm{~mm})$ & $\mathrm{D}_{60}(\mathrm{~mm})$ & $c_{u}=\frac{D_{60}}{D_{30}}$ & $C_{C}=\frac{\left(D_{30}\right)^{2}}{\left(D_{10}\right)\left(D_{60}\right)}$ \\
\hline 0.003 & 0.2 & 0.5 & 2.5 & 26.66
\end{tabular}

Piknometre deneyi neticesinde zemin numunesinin dane birim hacim ağırlığı 2.67 olarak belirlenmiştir. Atık lastik katkısının zemin numunesi üzerindeki etkisini belirleyebilmek için laboratuvarda kompaksiyon (modifiye proktor) ve kuru CBR deneyleri (su içerisinde 4 gün bekletilme yapılmaksızın) gerçekleştirilmiştir. Tabii (Doğal) zemin örneği üzerinde kompaksiyon deneyi yapılarak optimum su muhtevası ve maksimum kuru birim hacim ağırlık belirlenmiştir. Zeminlerin sınıflandırılması ve birim hacim ağırlıklarının belirlenmesinden sonra en önemli deney kompaksiyon deneyidir. Kompaksiyon deneyinin amacı sahada en iyi 
sıkışmanın sağlanabileceği, en yoğun durumdaki optimum su içeriğinin ve maksimum kuru birim hacim ağırlığın belirlenmesidir. Zemin danelerinin en iyi sıkışmayı gösterdiği optimum su muhtevası zeminlerin stabilizasyonu için oldukça önemlidir. Zeminde maksimum kuru birim hacim ağırlı̆̆ın elde edildiği optimum su muhtevasının bulunmasında Modifiye Proktor deneyi kullanılmıştır. Deney, zemin numunelerinin $152.4 \mathrm{~mm}$ çaplı bir silindir kalıp içerisine birbirine eşit olacak beş tabaka halinde serilmeleri ve serilen her bir tabaka üzerine $4.54 \mathrm{~kg}$ kütlesindeki tokmağın $457 \mathrm{~mm}$ yükseklikten $56 \mathrm{kez}$ serbest düşürülmesi ile sıkıştırılması esasına dayanmaktadır. Laboratuvarda gerçekleştirilen modifiye proktor deneyi sonucunda zeminin optimum su muhtevası \%9.7 ve maksimum kuru birim hacim ağırlı̆̆ 2.036 g/ $\mathrm{cm}^{3}$ olarak bulunmuştur. Kompaksiyon (modifiye proktor) deney sonuçları Tablo 3'de verilmiş olup, kompaksiyon deney eğrisi ise Şekil 2'de gösterilmiştir.

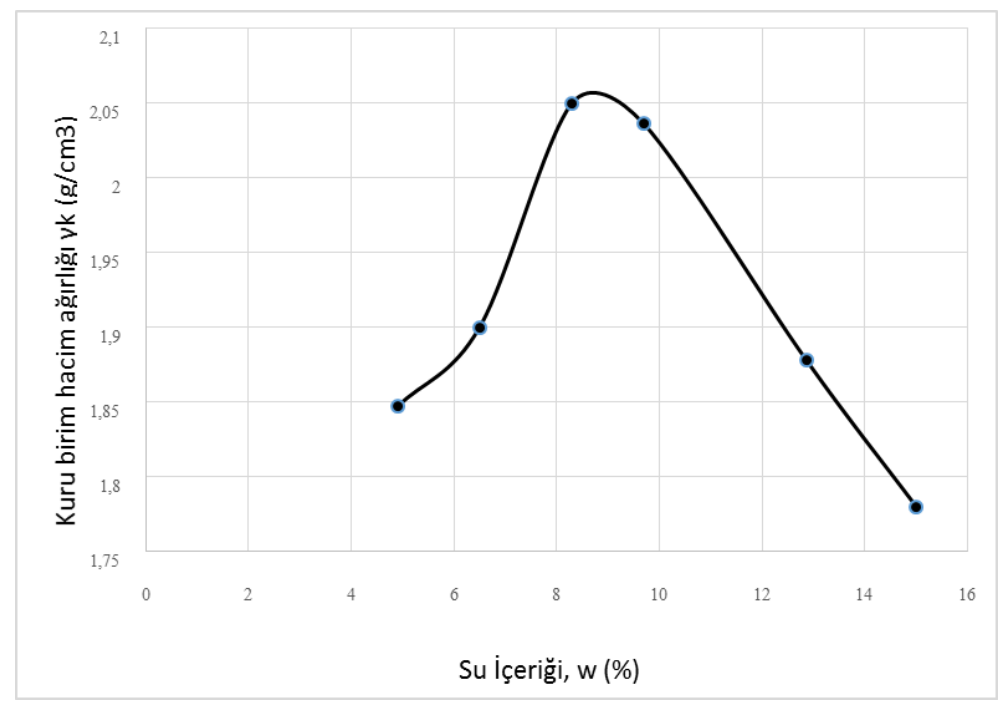

Şekil 2. Kompaksiyon Deney Eğrisi

Tablo 3. Kompaksiyon (modifiye proktor) deneyinden elde edilen parametreler

\begin{tabular}{|l|l|}
\hline Optimum Su Muhtevası, $w_{\text {opt }}(\%)$ & 9.7 \\
\hline Maksimum Kuru Birim Hacim Ağırlık, $\gamma_{\mathrm{k}}\left(\mathrm{g} / \mathrm{cm}^{3}\right)$ & 2.036 \\
\hline
\end{tabular}

Deneysel çalışmada, NKÜ Çorlu Mühendislik Fakültesi Yerleşkesi civarından getirilen kumlu numuneler, atık lastik parçacıklarıyla belli oranlarda karıştırılarak, lastik parçacıklarının, kumun kayma mukavemeti üzerindeki etkisi incelenmiştir. Su havuzu içerisinde 96 saat bekletilme yapılmadan kuru olarak gerçekleştirilen CBR deneyleri tabii zemin numunesi yanı sira tabii zemine $\% 1, \% 2$ oranlarında atık lastik katılarak $\% 8.0, \% 8.5, \% 8.75, \% 9.0$ ve $\% 9.5$ su muhtevaları değerlerinde tekrarlı olarak yapılmıştır. CBR (Kaliforniya taşıma oranı) deneyi kesit alanı $19.35 \mathrm{~cm}^{2}$ olan silindirik bir pistonun belirli bir hızla zemine itilmesiyle elde edilen yük-penetrasyon bağlantısının bulunmasını kapsar. 
Penetrasyonun herhangi bir değeri için, ölçülen yükün standart bir yüke oranı olarak tanımlanan CBR genellikle $2.5 \mathrm{~mm}$ 'lik penetrasyon için verilir. Ancak $5.0 \mathrm{~mm}$ 'lik bir penetrasyon için daha büyük bir değer çıkarsa, büyük olan değer verilir.

\section{BULGULAR VE TARTIŞMA}

Öğütülmüş atık lastik parçalarından oluşan katkı malzemelerinin, kumlu zemine karıştırılması ile kumlu zeminin CBR karakteristiklerinin nasıl değiştiğini araştırmak amacıyla yapılan deneyler, farklı su muhtevalarındaki zemin numunelerine ağırlıkça \%0, \%1 ve $\% 2$ granül atık lastik karıştırılarak gerçekleştirilmiştir. Kuru olarak yürütülen CBR deneyleri TS 1900-2 [14] standardında anlatıldığı gibi uygulanmıştır.

$\mathrm{Bu}$ çalışmada, farklı su muhtevaları ve değişik lastik yüzdelerinde hazırlanan karışımlar üzerinde gerçekleştirilen CBR deneyleri Tablo 4'de gösterilmiştir.

Tablo 4. Katkı Oranları ile Su muhtevalarına göre yürütülen CBR deneyleri

\begin{tabular}{cccc}
\hline \% Su Muhtevası, $\omega$ & \multicolumn{3}{c}{ Katkı Oranı (\%) } \\
\hline 8.0 & 0 & 1 & 2 \\
8.5 & 0 & 1 & 2 \\
8.75 & 0 & 1 & 2 \\
9.0 & 0 & 1 & 2 \\
9.5 & 0 & 1 & 2 \\
\hline
\end{tabular}

Şekil 3, Şekil 4 ve Şekil 5'de sırasıyla; katkısız, \%1 ve \%2 katkılı CBR deneylerinden elde edilen yük-penetrasyon eğrileri görülmektedir.

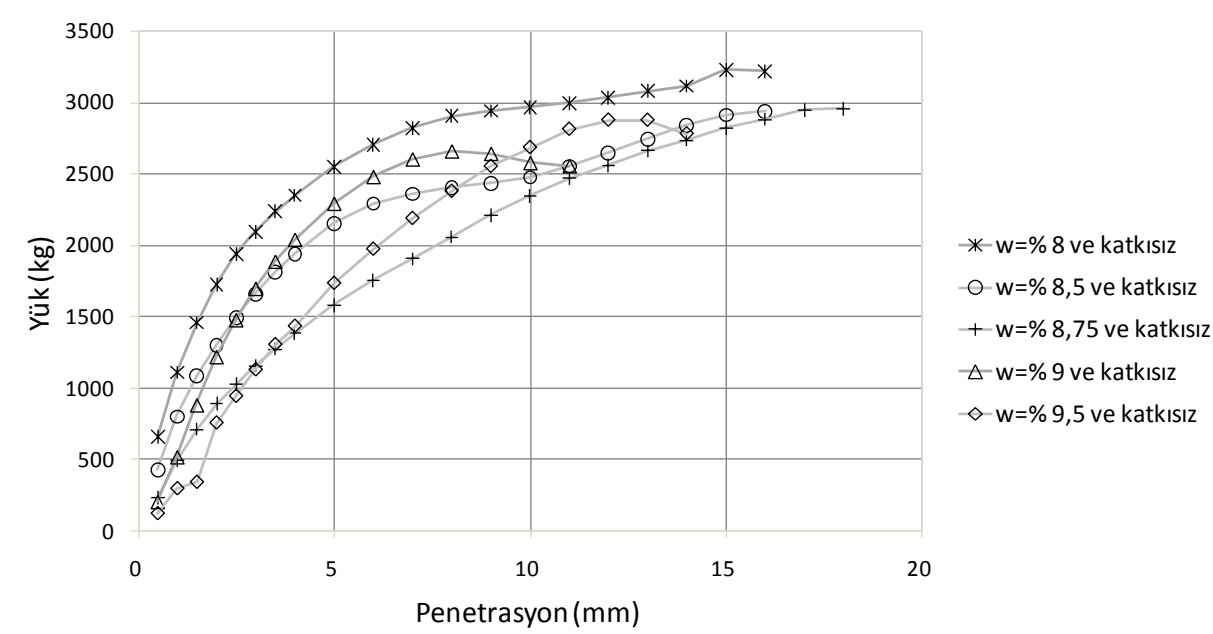

Şekil 3. Katkısız hazırlanan numuneler üzerinde yapılan CBR yük-penetrasyon eğrileri

Tablo 5 'de gerçekleştirilen deneylere ait standart yük değerleri ile deney sonucunda elde olunan CBR değerlerinin karşılaştırılması görülmektedir. CBR değerleri: 2.5 ve 5.00 mm'lik 
penetrasyon değerlerine göre hesaplanır ve elde edilen iki değerden yüksek olanı zeminin CBR değeri olarak alınır [14].

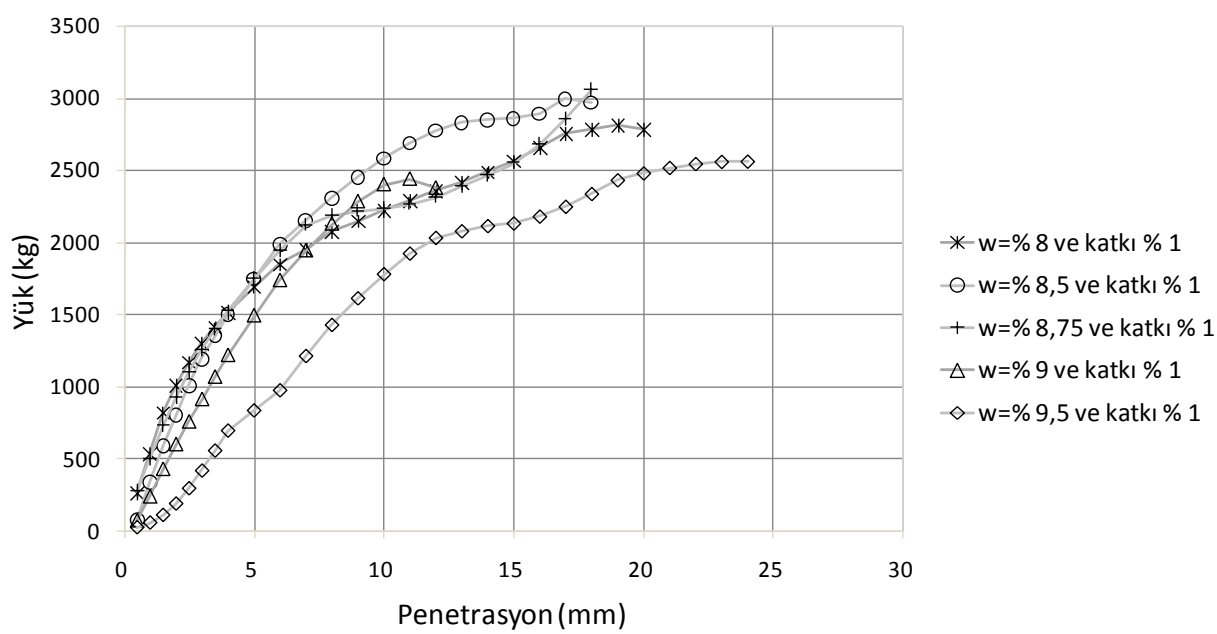

Şekil $4 \% 1$ katkılı numuneler üzerinde yapılan CBR yük-penetrasyon eğrileri

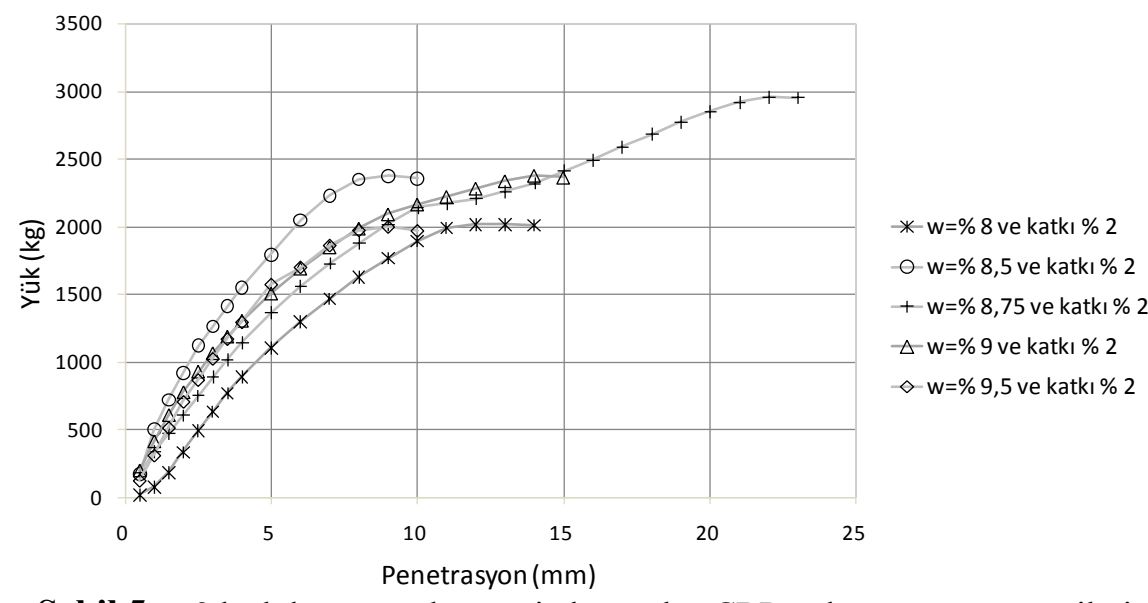

Şekil 5. \%2 katkılı numuneler üzerinde yapılan CBR yük-penetrasyon eğrileri

Tablo 5. Deney sonuçlarından bulunan CBR değerlerinin karşılaştırılması

\begin{tabular}{ccc}
\hline \% Su Muhtevası, $\boldsymbol{w}$ & \% Katkı Oranı & CBR değeri (\%) \\
\hline 8.0 & 0 & 142 \\
& 1 & 85 \\
& 2 & 54 \\
8.5 & 0 & 109 \\
& 1 & 85 \\
& 2 & 87 \\
8.75 & 0 & 77 \\
& 1 & 85 \\
9.0 & 2 & 66 \\
& 0 & 112 \\
& 1 & 73 \\
9.5 & 2 & 73 \\
& 0 & 85 \\
& 1 & 41 \\
& 2 & 77 \\
\hline
\end{tabular}




\section{SONUÇLAR}

$\mathrm{Bu}$ araştırmanın amacı; atık lastiklerin zemin iyileştirme uygulamalarında kullanılabileceği hususunda özellikle ülkemizdeki geoteknik alanındaki araştırmacıları bilgilendirmektir. $\mathrm{Bu}$ araştırmanın atık lastiklerin bertaraf edilmesi uygulamalarına 1şık tutması açısından da çevre yönetimine katkıda bulunacağına inanılmaktadır. Bu tür malzemelerin yeniden kullanılarak geri dönüşüme katılması çevrenin ve doğanın dengesinin korunabilmesi, doğaya verilen zararın minimuma indirilebilmesi ve ülke ekonomisi açısından oldukça önemlidir

Yapılan bu çalışmada; kumlu zeminlerin, değişik oranlarda öğütülmüş atık lastiklerden oluşan katkı malzemeleri ile mukavemetlerinde görülen iyileştirmeler araştırılmıştır. Deneysel çalışmada, NKÜ Çorlu Mühendislik Fakültesi Yerleşkesi civarından alınan kumlu zemin numuneleri üzerinde sırasıyla elek analizi, hidrometre, piknometre, kompaksiyon (modifiye proktor) ve kuru CBR deneyleri yapılmıştır.

Granülometri deney eğrisinden zemin numunesinin \%80 oranında kum içerdiği belirlenmiştir. Kompaksiyon deneyi sonucunda, zeminin arazide en iyi sıkışmayı gösterdiği optimum su muhtevası \%9.7, zeminin maksimum kuru birim hakim ağırlı̆̆ $2.036 \mathrm{~g} / \mathrm{cm}^{3}$ olarak bulunmuştur. Farklı su muhtevalarında gerçekleştirilen CBR deneyleri zemine ağırlıç̧a \%0, $\% 1$ ve $\% 2$ atık lastik karıştırılarak yapılmıştır. Atık lastik kullanılmadan gerçekleştirilen deneyde en yüksek CBR değeri \%142 ile \%8 su muhtevasında elde edilmiştir. \%1 atık lastik karıştırılarak yapılan deneyde en yüksek CBR değeri \%8 ile \%8.5 ve \%8.75 su muhtevası değerlerinde bulunmuştur. \%2 atık lastik karıştırılarak yapılan deneyde en yüksek CBR değeri $\% 8$ ile \%8.5 su muhtevası değerinde elde edilmiştir.

Yapılan deney sonuçları incelendiğinde, ögütülmüş atık lastiklerin karışım oranlarının artmasıyla kumlu zeminde CBR değerlerinde artış olmayıp aksine azalmalar gözlemlenmiştir. $\mathrm{Bu}$ çalışmayla, benzer konularda yapılan çalışmalara 1şık tutulacağı düşünülmekle beraber, sadece atık lastiklerin katkısıyla kumlu zeminlerde arzu edilen zemin iyileştirmelerinin sağlanamayacağı, sonucuna ulaşılmıştır.

Kumlu zeminlerde, diğer zemin türlerinin (kil ve/veya siltli zemin malzemelerin) çeşitli oranlarda karışımları da düşünülerek, bu tür öğütülmüş atık lastik katkılı iyileştirme arayışlarının gelecek çalışmalarda da devam edilmesi daha anlamlı olacaktır.

\section{Teşekkürler}

Yazarlar, NKUBAP.00.17.AR.13.04 no'lu Atık Lastiklerin Zemin İyileştirilmesinde Kullanımı isimli projenin desteklenmesi nedeniyle Namık Kemal Üniversitesi Bilimsel Araştırma Projeleri Birimi’ne ve projedeki katkı malzemesini (kıyılmış atık lastiği) sağlayan Lokman Geri Kazanım A.Ş. firmasına teşekkür ederler. 


\section{KAYNAKLAR}

[1] M.E. Kalinski, B.T. Hippley, The effect of water content and cement content on the strength of portland cement-stabilized compacted fly ash. Fuel. 84(14-15) (2005) 1812-1819.

[2] Z. Angın, A. Angın, Şişen Killerin Geoteknik Özelliklerinin İyileştirilmesi. 6. Geoteknik Sempozyumu Bildiriler Kitab1, sf. 365-380, 26-27 Kasım 2015, Adana, Türkiye.

[3] A. Şenol, T. Edil, Uçucu Kül ile Stabilize Edilen Yumuşak Zeminlerin CBR Sonuçlarının Değerlendirilmesi. Zemin Mekaniği ve Temel Mühendisliği ZM10. Onuncu Ulusal Kongresi Bildiriler Kitab1, sf. 275-280,16-17 Eylül 2004, İstanbul, Türkiye.

[4] M. Ghazavi, Shear strength characteristics of sand-mixed with granular rubber. Geotechnical and Geological Engineering. 22 (2004) 401-416.

[5] Y.W. Yoon, S.H. Cheon, D.S. Kang, Bearing capacity and settlement of tirereinforced sands. Geotextiles and Geomembranes. 22(5) (2004) 439-453.

[6] Ö. Tan, Ş. Zaimoğlu, S. Hınıslığlu, S. Altun, Ilave Malzemelerle Stabilize Edilmiş Kumlarda Kayma Direnci Parametrelerinin Taguchi Yöntemi ile Belirlenmesi. Zemin Mekaniği ve Temel Mühendisliği Dokuzuncu Ulusal Kongresi Bildiriler Kitabı 2, sf. 545554, 21-22 Ekim 2002, Eskişehir, Türkiye.

[7] P.V. Sivapullaiah, H.L. Kantha, K.M. Kıran, Geotechnical properties of stabilised Indian red earth. Geotechnical and Geological Engineering. 21(4) (2003) 399-413.

[8] E. Çokça, F. Toktaş, Dispersif Bir Kilin C-Tipi Uçucu Kül ile Stabilizasyonu. Zemin Mekaniği ve Temel Mühendisliği 9. Ulusal Kongresi Bildiriler Kitabı 2, sf. 659-668, 2122 Ekim 2002, Eskişehir, Türkiye.

[9] S.R. Kaniraj, V.G. Havanagi, Compressive strength of cement stabilized fly ash-soil mixtures. Cement and Concrete Research. 29 (1999) 673- 677.

[10]E. Tüdeş, Zeminlerin kireç ve çimento katkısı ile çözümü. Yüksek Lisans Tezi, Karadeniz Teknik Üniversitesi, Trabzon, (1996).

[11]J.N. Mandal, A. Viswamohan, Performance Studies on California Bearing Ratio Values Using Geosynthetics. Proceedings of the International Workshop on Geotextiles Prooceeding Book, pp. 255-258, 22-29 November 1989, Bangalore, India.

[12] N.R. Krisnaswamy, H.B. Raghavendra, Behavior of Reinforced Earth under Direct Shear Test. Proceedings of the First Indian Geotextiles Conference on Reinforced Soil Prooceeding Book, pp. 47-52, 8-9 December 1988, Mumbai, India.

[13] K. Li, Use of cement, fly ash and EER admixture in soil stabilization. Master's Thesis, Tamkang University, New Taipei City (1988).

[14]TS 1900-2, Inşaat mühendisliğinde zemin laboratuvar deneyleri - Bölüm 2: Mekanik özelliklerin tayini, Türk Standartları Enstitüsü, Ankara, (2006). 